\title{
Health Numeracy Confidence among Racial/Ethnic Minorities in HINTS 2007: Sociodemographic, Attitudinal, and Knowledge Correlates
}

\author{
HONG HUANG, YIU MING CHAN, and DONG FENG
}

\begin{abstract}
Health numeracy skills help people interpret health risks, and make effective medical decisions. Lower health numeracy confidence was observed for blacks and Hispanic groups than whites. Little is known about the important factors that explain racial differences in health numeracy confidence. For this study, we used a nationally representative, crosssectional data sample of 4,610 U.S. adults from the National Cancer Institute's 2007 Health Information National Trends Survey. Bivariate (Chisquares) and multiple logistic regression analyses were conducted to identify the contribution factors that predict health numeracy confidence. Nonlinear Fairlie decompositions were used to quantify the factor contributions to racial differences in health numeracy confidence. The priority rankings of the important factors to explain the health numeracy confidence racial and ethnic disparities are different depending on the particular racial and ethnic group. Diverse, culturally appropriate approaches are needed to improve numeracy confidence for specific racial and ethnic groups.
\end{abstract}

\section{Introduction}

There is a growing interest in understanding the associations between health numeracy and disparities in healthcare (Schapira, Fletcher, Gilligan, King, Laud, Matthews, Neuner and Hayes 2008). Health numeracy, a part of health literacy, is defined as 'The degree to which individuals have the capacity to access, process, interpret, communicate, and act on numerical, quantitative, graphical, biostatistical, and probabilistic health information needed to make effective health decisions' (Golbeck, Ahlers-Schmidt, Paschal and Dismuke 2005:375). Health numeracy is critical since it can impact how patients process information. It allows patients to interpret information related to the probability of health outcomes, including risk, severity, and outcomes of disease (Golbeck et al 2005), and it helps patients make decisions regarding the risks and benefits of a given medical treatment. For example, a patient's health numeracy level can be used to indicate the patient's capability of understanding the numbers when referring to health or disease states, the efficacy of an intervention, or other expected health 
outcomes (Golbeck et al 2005). An individual's health numeracy is influenced by language, culture, and social capital; additionally, the healthcare system demands adequate health numeracy (Zarcadoolas, Pleasant and Greer 2006, Nutbeam 2008). There is an increased focus on measuring how confident and comfortable people feel about their numeracy ability to impact their medical decision making (Reyna, Nelson, Han and Dieckmann 2008). This research demonstrates that elderly people, nonwhite ethnic minorities, or people with low education levels lack numeracy confidence (Nelson, Reyna, Fagerlin, Lipkus and Peters 2008, Osborn, Cavanaugh, Wallston, White and Rothman 2009, Smith, Wolf and Wagner 2010). Low numeracy has also been associated with poor health knowledge and attitudes, limited access or use of the internet, self-reported poor health, undesirable health outcomes, and health disparities (Baker, Parker, Williams, Clark and Nurss 1997, Williams, Baker, Parker and Nurss 1998, Berkman, DeWalt and Pignone 2004, DeWalt, Berkman, Sheridan, Lohr and Pignone 2004, Jensen, King, Davis and Guntzviller 2010). Studies also found that minority patients might be more likely to be hospitalized and less likely to use clinical preventive services than those with adequate health numeracy (Nelson et al 2008).

Despite the population growth of minorities, there is a gap in the current literature addressing issues related to health numeracy confidence for nonwhite racial groups. Surveys of ethnic minorities related to health numeracy have been performed in specific clinics serving minority communities (Osborn, Paasche-Orlow, Davis and Wolf 2007, Osborn et al 2009), yet racial and ethnic disparity related to health numeracy have not yet been investigated in a nationally representative sample. Little is known about the most important factors that explain these racial/ethnic differences in health numeracy confidence. This study examines the association between ethnicity and health numeracy confidence. A deeper understanding of the multiple factors, including social economics, health behaviors, attitudes and education that contribute to the racial differences in health numeracy confidence could improve health numeracy in general as well as within minority groups. Additionally, this understanding could be used to create more targeted health interventions to reduce the numeracy gaps for minority groups, thereby enhancing their medical decisions and reducing risk of disease. In this research, we studied the following research questions using the US national survey sample: 1) Are there any differences among racial and ethnic groups for numeracy confidence? 2) What are the factors correlated with racial/ethnic numeracy confidence differences? 


\section{Methods}

\section{Sample}

The 2007 National Cancer Institute's HINTS

(http://hints.cancer.gov/) cross-sectional survey data of 7,674 American adults were collected either by telephone or postal mail. The survey asked hundreds of questions about cancer related knowledge, health services, attitudes and behavior. For this study, we focused on the questions pertaining to subjective statistical confidence ('In general, how easy or hard do you find it to understand medical statistics?") on a four-point Likert scale. The answers were dichotomized into 'very easy/easy' or 'hard/very hard' for further analysis. All of the 'don't know' and 'refused' responses for the studying variables were counted as missing. There were 7,173 respondents providing information about their ethnicity in HINTS data. In HINTS, it groups people ethnically into 'Non-Hispanic White', 'Hispanic or Latino', and 'Non-Hispanic Black' and others. To make it simple in the rest of paper, we used the term of 'white', 'Hispanic', and 'black' to represent these social ethnic groups. The final sample used for the study, excluding all missing data, came to 4,610, of which 3,810 were white, 389 were Hispanic, and 441 were black. The discussion of the study focuses on these three racial groups (white, Hispanic, and black). Several independent variables were incorporated in the analysis to reflect demographic status, attitudes, health behaviors, and knowledge.

We considered variables related to sociodemographics, healthcare attitudes, and health behaviors that might explain the gaps between whites and minorities in health numeracy confidence. The sociodemographic variables included in our analysis were race, ethnicity, gender, age, education, income, marital status, and insurance status. Attitude-related variables were trust of online information, self-efficacy, and confidence in one's ability to find health information, and healthcare quality rating. Some variables were knowledge related, such as whether the participant had heard of the Center for Disease Control and Prevention (CDC) or were aware of genetic testing. We also included variables related to cancer information seeking, online access, and information overload, for the analysis.

\section{Statistical Analysis}

All statistical analyses in this study were conducted using STATA 10.1 software (College Station, Texas, USA). The percentage distribution of all the variables across racial and ethnic groups was examined and their bivariate statistics (Chi-square) were calculated. Multivariate logistic regression analysis was used to examine the relationships between race/ethnicity and the dichotomous outcome confidence/lack of confidence 
regarding health numeracy by considering independent variables related to sociodemographic, attitudinal, and knowledge variables by race/ethnicity.

The Fairlie decomposition technique identifies the individual contribution of independent variables to explain the differences across racial/ethnic groups by computing the change in the average predicted probability (Fairlie 1999, Fairlie 2005). Coefficient estimates from a logistic regression based on the sample of the two groups are used to obtain predicted probabilities (Fairlie 1999, Fairlie 2005). Since the sample size of whites was extremely high compared to the sample size of blacks, and because the non-linear decomposition required one-to-one matching of cases between the two groups, we used a random drawing of whites to create a sample size equal to the full sample of blacks (Fairlie 2005, Pagán, $\mathrm{Su}, \mathrm{Li}$, Armstrong and Asch 2009). The contributions to the white-black gap for each single variable in the regression were calculated. This process was repeated 500 times to generate the mean results to the white-black gap and the white-Hispanics gap in health numeracy confidence.

\section{Results}

Almost $44 \%$ of Hispanics reported that they lacked confidence in their ability to understand medical statistics, followed by about $38 \%$ blacks, and $34 \%$ of non-Hispanic whites (Table 1). The three racial and ethnic groups differed significantly between high numeracy confidence and low confidence respondents $(p<0.001)$ grouped by educational levels (Table 1 ). Both black and Hispanic respondents tended to have lower educational attainment, income, and insurance plan enrolment rates than whites. Whites with health numeracy confidence were more likely to have online access and exhibit cancer information seeking behavior. They were also most likely to be aware of the Center for Disease Control and Prevention (CDC) and of genetic testing than blacks and Hispanics. About half of the low health numeracy confident Hispanic respondents had not heard about the GDC. In terms of their attitudes towards getting health information, Hispanics with low numeracy confidence showed a lower rate of health information seeking confidence than blacks and whites.

Multivariate linear logistic regression models were estimated by using health numeracy confidence as the dependent variable. The unadjusted Odds ratio indicated that being Hispanic was a significant predictor while being black was not. After adjusting with socioeconomic and other factors, the racial difference was no longer significant. This indicated that the predictors in the logistic model can well explain the racial difference between Hispanics and whites for numeracy confidence. Results from Table 2 also showed that health numeracy confidence correlated strongly with younger respondents who had higher education levels. In addition, 
respondents with health numeracy confidence showed stronger trust for health information found online, higher ratings for the quality of healthcare, and higher self-efficacy. They were also active information seekers with more online access than was typical for other cohorts.

In order to understand the numeracy confidence gaps among the Hispanics-whites racial groups, using the Fairlie decomposition analysis, we found that about $81 \%$ of the $9.81 \%$ difference in health numeracy confidence between whites and Hispanics (Table 3) could be explained using the variables included in the logistic regression models. The most important factors affecting the white-Hispanic gap were education (24.9\%), online access $(17.1 \%)$, confidence in their ability to get health information if needed (16.4\%), and awareness of the CDC (14.8\%).

\section{Discussion}

This study has contributed several new findings. First, the results show that health numeracy confidence is considerably lower among the U.S. Hispanic population than the white population. Second, the results reveal that education, online access, self-perceived ability to get health information, and the high quality healthcare rating are among the influential factors underlying these majority-minority gaps. Third, about $80 \%$ of the whiteHispanic gap in health numeracy confidence could be explained by racial differences. This indicates that uniform policy remedies may not have the same effects for minority groups, and that optional strategies might be proposed to improve health numeracy among different racial and ethnic groups.

Education and online access are the most important factors that contribute to the white-Hispanic gap in health numeracy confidence. This finding is consistent with that of Fagerlin, Zikmund-Fisher, Ubel, Jankovic, Derry and Smith (2007), who found that disparities in information seeking behaviors were observed among Hispanics, and further, that Hispanics are more likely to have unequal access to health information or have sufficient skills to find and use health information. Similarly, Jensen et al (2010) contends that minorities with less online access have a correlating low numeracy confidence. Although many researchers have considered the racial and ethnic differences in educational attainment and online access, this study indicates that addressing these factors may correct the observed racial gaps.

Lack of awareness of both the CDC and genetic testing could explain many of the white-minority gaps in health numeracy confidence (Portnoy, Roter and Erby 2010). The CDC sponsors a number of ongoing health literacy awareness campaigns and the development of health literacy material which target minority populations and which may increase 
numeracy confidence for these groups. However, new approaches to cancer risk assessment, such as genetic testing, require that patients have a high level of numeracy skills in order to interpret the results so they may also require awareness campaigns.

The results of this study are consistent with those of (Peters, Dieckmann, Västfjäll, Mertz, Slovic and Hibbard 2009) which indicated that minorities show lower comprehension of numerical presentations of risk compared to whites, and further, that low numeracy confidence affects ability to interpret the quality of health service people received as well as a greater susceptibility to extraneous factors or distortions of information overload (Reyna et al 2008). In other words, poor numeracy skills affect people's ability to process information. As a result, they might face the challenge of too much information and find it difficult to interpret the numerical meanings from multiple reports. Our data support that of Reyna et al (2008) and Peters et al (2009) who argue that reducing information overload burdens by organizing and representing the information more effectively could help minorities process relevant information more thoroughly, thereby reducing the burden of information overload.

Previous studies reported that self-efficacy has associations with health numeracy skills for specific patient groups (Osborn, Cavanaugh, Wallston and Rothman 2010). Self-efficacy indicates a person's confidence in performing goal-directed behaviors (Wallston, Rothman and Cherrington 2007). Self-efficacy includes several skills, such as obtaining information and self-caring (Osborn et al 2010). Interestingly, this study found that higher self-efficacy in health information retrieval skills reduced racial gaps for both Hispanic and blacks in health numeracy confidence.

Numeracy is the ability to obtain, access, and interpret numeric information. Efficacy in finding health information may correlate to proficiency in numeracy. The study findings suggest that any initiative to promote health numeracy could vary in its effect on different racial and ethnic groups. Customized strategies targeted to the individual or social group based on these findings could result in more effective interventions (Noar, Benac and Harris 2007).

Previous findings have documented the importance of health numeracy for cancer risk prevention (Baker et al 1997, DeWalt et al 2004, Nelson et al 2008, Smith, Wolf and Wagner 2010). Despite these findings, it should be noted that improving health numeracy for racial and ethnic minorities is perhaps only the initial step to reducing racial and ethnic disparities. Wide disparities exist across racial and ethnic groups in education, knowledge, and information seeking behaviors and these inevitably have a large impact on capacity to transform health numeracy confidence to actual utilization when needed. 
This study had several limitations. While the study found socioeconomic and demographic factors that relate to health numeracy confidence, there are certainly other related factors that were not included due to data constraints (e.g., decision making with health provider recommendations). In addition, this research assesses respondents' subjective numerical confidence without investigating objective numerical capability. Only one variable: numeracy confidence was provided to be assessed in HINTS. Future research will extend to investigating objective numeracy since individuals may over or underestimate their numeracy skills. Objective numeracy may differ greatly from subjective numeracy when it comes to health interventions and outcomes. Despite these limitations, the findings from this study highlight the differences between racial groups and identify the relatively important factors that explain racial differences in health numeracy confidence and suggest directions for potential policy interventions.

\section{Conclusion}

The results show that health statistical confidence is considerably lower among Hispanics minority U.S. populations in comparison to whites. Numeracy confidence in blacks is not statistically different from that of whites. Education levels, online access, healthcare quality rating, and confidence of finding health information are among the most influential factors underlying the whites-Hispanics gaps. These findings could help identify policy remedies to address the gaps in health numeracy confidence, such as tailored campaigns that focus on cultural, attitudinal, knowledge, and socioeconomic factors. To achieve these objectives, we must continue to study how to measure health literacy, which interventions can improve health literacy levels, and the relationships between health literacy and health outcomes.

\section{Acknowledgements}

This study was funded by the USF CAS faculty research and development grant.

\section{References:}

Baker, David, Parker, Ruth, Williams, Mark, Clark, Scott, and Nurss, Joanne (1997) The Relationship of Patient Reading Ability to Selfreported Health and Use of Health Services, American Fournal Public Health, vol 87, pp 1027-1030.

Berkman, Nancy, DeWalt, Darren, and Pignone, Michael (2004) Literacy and Health Outcomes. Summary, Evidence Report/Technology Assessment No. 87. Rockville: AHRQ; (Prepared by RTI International, University of North Carolina Evidence-based Practice Genter under Contract No. 
290-02-0016) AHRQ Publication No. 04-E007-1: Agency for Healthcare Research and Quality.

DeWalt, Darren, Berkman, Nancy, Sheridan, Stacey, Lohr, Kathleen, and Pignone, Michael (2004) Literacy and Health Outcomes: A systematic review of the literature, Fournal of General Internal Medicine, vol 19, pp 1228-1239.

Fagerlin, Angela, Zikmund-Fisher, Brian, Ubel, Peter, Jankovic, Aleksandra, Derry, Holly, and Smith, Dylan M (2007) Measuring Numeracy without a Math Test: Development of the subjective numeracy scale, Medical Decision Making, vol 27, no 5, pp 672-680.

Fairlie, Robert (1999) The Absence of the African-American Owned Business: An analysis of the dynamics of self-employment, Fournal of Labor Economics, vol 17, pp 80-108.

Fairlie, Robert (2005) An Extension of the Blinder-Oaxaca Decomposition Technique to Logit and Probit Models, Fournal of Economic and Social Measurement, vol 30, pp 305-316.

Golbeck, Amanda, Ahlers-Schmidt, Carolyn, Paschal, Angelia, Dismuke, Edwards (2005) A Definition and Operational Framework for Health Numeracy, American Fournal of Preventive Medicine, vol 29, pp 375-376.

Jensen, Jakob, King, Andy, Davis, LaShara, and Guntzviller, Lisa (2010) Utilization of Internet Technology by Low-income Adults: The role of health literacy, health numeracy, and computer assistance, Fournal of Aging and Health, vol 22, no 6, pp 804-826.

Nelson, Wendy, Reyna, Valerie, Fagerlin, Angela, Lipkus, Isaac, and Peters, Ellen (2008) Clinical Implications of Numeracy: Theory and practice Annals of Behavioral Medicine, vol 35, no 3, pp 261-274.

Noar, Seth, Benac, Christina, and Harris, Melissa (2007) Does Tailoring Matter? Meta-analytic review of tailored print health behavior change interventions, Psychological Bulletin, vol 133, pp 673-693.

Nutbeam, Don (2008) The Evolving Concept of Health Literacy, Social Science and Medicine, vol 67, pp 2072-2078.

Osborn, Chandra, Cavanaugh, Kerri, Wallston, Kenneth, White, Richard, and Rothman, Russell (2009) Diabetes Numeracy: An overlooked factor in understanding racial disparities in glycemic control, Diabetes Care, vol 32, no 9, pp 1614-1619.

Osborn, Chandra, Cavanaugh, Kerri, Wallston, Kenneth, and Rothman, Russell (2010) Self-efficacy Links Health Literacy and Numeracy to Glycemic Control, Fournal of Health Communication, vol 15, no S2, pp 146-158.

Osborn, Chandra, Paasche-Orlow, Michael, Davis, Terry, and Wolf, Michael (2007) Health literacy: An overlooked factor in understanding HIV health disparities, American Fournal of Preventive Medicine, vol 33, no 5, pp 374-378. 
Pagán, José, Su, Dejen, Li, Lifeng, Armstrong, Katrina, and Asch, David (2009) Racial and ethnic disparities in awareness of genetic testing for cancer risk, American Fournal of Preventive Medicine, vol 37, no 6, pp 524530.

Peters, Ellen, Dieckmann, Nathan, Västfjäll, Daniel, Mertz, C.K., Slovic, Paul, and Hibbard, Judith H (2009) Bringing meaning to numbers: The impact of evaluative categories on decisions, Fournal of Experimental Psychology, vol 15, no 3, pp 213-227.

Portnoy, David, Roter, Debra and Erby, Lori (2010) The role of numeracy on client knowledge in BRCA genetic counseling, Patient Education Counseling vol 81, pp 131-6.

Reyna, Valerie, Nelson, Wendy, Han, Paul, and Dieckmann, Nathan (2008). How numeracy influences risk comprehension and medical decision making, Psychological Bulletin, vol 135, no 6, pp 943-973.

Schapira, Marilyn, Fletcher, Kathlyn, Gilligan, Mary Ann, King, Toni, Laud, Purushottam, Matthews, Alexendra, Neuner, Joan, and Hayes, Elisabeth (2008) A framework for health numeracy: how patients use quantitative skills in health care, Fournal of health Communication, vol 13, pp 501-517.

Smith, Samuel, Wolf, Michael, and von Wagner, Christian (2010) Socioeconomic status, statistical confidence, and patient-provider communication: an analysis of the Health Information National Trends Survey (HINTS 2007), Fournal of health Communication vol 15, pp 169-185.

Wallston, Kenneth, Rothman, Russell, and Cherrington, Andrea (2007) Psychometric properties of the Perceived Diabetes Self-Management Scale (PDSMS). Fournal of Behavioral Medicine, vol 30, no 5, pp 395401.

Williams, Mark, Baker, David, Parker, Ruth, and Nurss, Joanne (1998) Relationship of functional health literacy to patients' knowledge of their chronic disease, Archives of Internal Medicine, vol 158, pp 166-172.

Zarcadoolas, Christina, Pleasant, Andrew, and Greer, David (2006) Advancing health literacy: A framework for understanding and action, JosseyBass, San Francisco, CA. 
Table 1. Respondents with health numeracy confidence (No or Yes) grouped by Race/Ethnicity

\begin{tabular}{|c|c|c|c|c|c|c|c|c|c|}
\hline \multirow[b]{2}{*}{ Age } & \multicolumn{3}{|c|}{ White (\%) } & \multicolumn{3}{|c|}{ Black (\%) } & \multicolumn{3}{|c|}{ Hispanic (\%) } \\
\hline & No & Yes & $\begin{array}{l}\text { P value } \\
<0.001\end{array}$ & No & Yes & $\begin{array}{c}\text { P value } \\
0.292\end{array}$ & No & Yes & $\begin{array}{c}\text { P value } \\
0.009\end{array}$ \\
\hline $18-34$ & 15 & 9 & & 20 & 15 & & 33 & 25 & \\
\hline $35-49$ & 25 & 24 & & 25 & 30 & & 34 & 29 & \\
\hline $50-64$ & 36 & 36 & & 41 & 38 & & 24 & 31 & \\
\hline $65-74$ & 16 & 17 & & 11 & 11 & & 6 & 8 & \\
\hline $75+$ & 9 & 13 & & 3 & 7 & & 2 & 8 & \\
\hline Born in USA & & & 0.188 & & & 0.726 & & & 0.146 \\
\hline Yes & 96 & 97 & & 94 & 93 & & 58 & 51 & \\
\hline No & 4 & 3 & & 6 & 7 & & 42 & 49 & \\
\hline Education & & & $<0.001$ & & & $<0.001$ & & & $<0.001$ \\
\hline Below high school & 3 & 6 & & 7 & 14 & & 16 & 32 & \\
\hline High school & 18 & 29 & & 23 & 33 & & 21 & 29 & \\
\hline Some college & 31 & 30 & & 33 & 37 & & 38 & 23 & \\
\hline College graduate & 49 & 35 & & 36 & 17 & & 26 & 16 & \\
\hline Gender & & & 0.036 & & & 0.471 & & & 0.066 \\
\hline Male & 41 & 37 & & 28 & 31 & & 33 & 42 & \\
\hline Female & 59 & 63 & & 72 & 69 & & 67 & 58 & \\
\hline Income & & & $<0.001$ & & & 0.007 & & & 0.084 \\
\hline$<\$ 20,000$ & 8 & 13 & & 23 & 37 & & 22 & 32 & \\
\hline$\$ 20,000<\$ 35,000$ & 12 & 16 & & 19 & 16 & & 16 & 22 & \\
\hline$\$ 35,000<\$ 50,000$ & 13 & 14 & & 14 & 17 & & 13 & 13 & \\
\hline$\$ 50,000<\$ 75,000$ & 21 & 20 & & 15 & 12 & & 18 & 13 & \\
\hline$\$ 75,000$ or more & 42 & 32 & & 24 & 12 & & 28 & 19 & \\
\hline Others (Refused) & 4 & 5 & & 5 & 5 & & 2 & 1 & \\
\hline Insurance & & & 0.898 & & & 0.418 & & & 0.768 \\
\hline Yes & 94 & 94 & & 82 & 85 & & 79 & 80 & \\
\hline No & 6 & 6 & & 18 & 15 & & 21 & 20 & \\
\hline Marital status & & & 0.492 & & & 0.157 & & & 0.15 \\
\hline Married & 34 & 35 & & 58 & 64 & & 34 & 42 & \\
\hline Other & 66 & 65 & & 42 & 36 & & 66 & 58 & \\
\hline Cancer info overload & & & $<0.001$ & & & $<0.001$ & & & 0.004 \\
\hline Strongly agree & 68 & 82 & & 65 & 80 & & 67 & 80 & \\
\hline Somewhat agree & 32 & 18 & & 35 & 20 & & 33 & 20 & \\
\hline
\end{tabular}




\begin{tabular}{|c|c|c|c|c|c|c|c|c|c|}
\hline & \multicolumn{3}{|c|}{ White (\%) } & \multicolumn{3}{|c|}{ Black (\%) } & \multicolumn{3}{|c|}{ Hispanic (\%) } \\
\hline \multirow{2}{*}{\multicolumn{3}{|c|}{$\begin{array}{l}\text { No } \\
\text { Confident to get health info }\end{array}$}} & $P$ value & No & Yes & P value & No & Yes & $P$ value \\
\hline & & & $<0.001$ & & & $<0.001$ & & & $<0.001$ \\
\hline Full confident & 71 & 52 & & 71 & 49 & & 56 & 44 & \\
\hline Very confident & 24 & 38 & & 23 & 33 & & 33 & 30 & \\
\hline Some confident & 5 & 10 & & 6 & 18 & & 11 & 26 & \\
\hline \multicolumn{3}{|c|}{ Confident to self caring } & $<0.001$ & & & $<0.001$ & & & 0.134 \\
\hline Full confident & 23 & 15 & & 28 & 18 & & 23 & 21 & \\
\hline Very confident & 55 & 48 & & 50 & 43 & & 39 & 43 & \\
\hline Some confident & 21 & 37 & & 21 & 39 & & 31 & 40 & \\
\hline Heard of CDC & & & $<0.001$ & & & 0.002 & & & 0.001 \\
\hline Yes & 92 & 85 & & 86 & 75 & & 67 & 50 & \\
\hline No & 8 & 15 & & 14 & 25 & & 33 & 50 & \\
\hline \multicolumn{3}{|c|}{$\begin{array}{l}\text { Heard of genetic } \\
\text { test }\end{array}$} & $<0.001$ & & & 0.62 & & & 0.08 \\
\hline Yes & 40 & 32 & & 28 & 25 & & 34 & 26 & \\
\hline No & 60 & 69 & & 72 & 75 & & 66 & 74 & \\
\hline \multicolumn{3}{|c|}{ Looking for cancer information } & $<0.001$ & & & 0.165 & & & $<0.001$ \\
\hline Yes & 56 & 49 & & 42 & 35 & & 49 & 27 & \\
\hline No & 44 & 51 & & 58 & 65 & & 51 & 73 & \\
\hline \multicolumn{3}{|l|}{ Online access } & $<0.001$ & & & $<0.001$ & & & $<0.001$ \\
\hline Yes & 85 & 71 & & 70 & 52 & & 72 & 47 & \\
\hline No & 15 & 29 & & 30 & 48 & & 28 & 53 & \\
\hline \multicolumn{3}{|c|}{ Rating quality healthcare } & $<0.001$ & & & 0.147 & & & 0.807 \\
\hline Excellent & 41 & 29 & & 33 & 26 & & 29 & 27 & \\
\hline Very good & 41 & 43 & & 40 & 38 & & 34 & 35 & \\
\hline Good & 15 & 21 & & 17 & 22 & & 25 & 23 & \\
\hline Fair & 4 & 8 & & 10 & 14 & & 11 & 14 & \\
\hline \multicolumn{3}{|c|}{ Trust health info on Internet } & $<0.001$ & & & $<0.001$ & & & $<0.001$ \\
\hline A lot & 23 & 16 & & 26 & 11 & & 33 & 18 & \\
\hline Some & 56 & 53 & & 50 & 47 & & 43 & 37 & \\
\hline A little & 15 & 18 & & 16 & 24 & & 16 & 17 & \\
\hline Not at all & 7 & 14 & & 8 & 17 & & 9 & 29 & \\
\hline
\end{tabular}


Table 2. ORs of respondents who reported health numeracy confidence from HINTS 2007 survey

\begin{tabular}{|c|c|c|c|c|}
\hline & Unadjusted OR & $(95 \% \mathrm{CI})$ & Adjusted OR & (95\% CI) \\
\hline \multicolumn{5}{|l|}{ Race } \\
\hline White & 1 & & 1 & \\
\hline Hispanic & $0.66^{* * *}$ & $(0.53-0.81)$ & 0.88 & $(0.69,1.13)$ \\
\hline Black & 0.83 & $(0.68-1.02)$ & 0.98 & $(0.78,1.22)$ \\
\hline \multicolumn{5}{|l|}{ Age } \\
\hline $18-34$ & & & 1 & \\
\hline $35-49$ & & & $0.64 * * *$ & $(0.52,0.80)$ \\
\hline $50-64$ & & & $0.68^{* * *}$ & $(0.55,0.84)$ \\
\hline $65-74$ & & & $0.72 * *$ & $(0.56,0.93)$ \\
\hline $75+$ & & & $0.61^{* * *}$ & $(0.45,0.82)$ \\
\hline \multicolumn{5}{|l|}{ Education } \\
\hline Less than high school & & & 1 & \\
\hline High school graduate & & & 1.07 & $(0.79,1.43)$ \\
\hline Some college & & & $1.41 * *$ & $(1.05,1.89)$ \\
\hline College graduate & & & $1,61^{* * *}$ & $(1.18,2.19)$ \\
\hline \multicolumn{5}{|l|}{ Gender } \\
\hline Male (reference) & & & 1 & \\
\hline Female & & & $0.88^{*}$ & $(0.77,1.00)$ \\
\hline \multicolumn{5}{|l|}{ Income } \\
\hline$<\$ 20,000$ & & & 1 & \\
\hline$\$ 20,000$ to $<\$ 35,000$ & & & 0.94 & $(0.77,1.14)$ \\
\hline$\$ 35,000$ to $<\$ 50,000$ & & & 1 & $(0.81,1.13)$ \\
\hline$\$ 50,000$ to $<\$ 75,000$ & & & 0.96 & $(0.80,1.12)$ \\
\hline$\$ 75,000$ or more & & & 0.88 & $(0.66,1.21)$ \\
\hline Others (Refused) & & & 1.01 & $(0.7,1.45)$ \\
\hline \multicolumn{5}{|l|}{ Cancer info overload } \\
\hline Strongly agree & & & 1 & \\
\hline Somewhat agree & & & $1.8 * * *$ & $(1.54,2.10)$ \\
\hline
\end{tabular}




\begin{tabular}{|c|c|c|c|}
\hline Unadjusted OR & $(95 \% \mathrm{CI})$ & Adjusted OR & $(95 \% \mathrm{CI})$ \\
\hline \multicolumn{4}{|l|}{$\begin{array}{l}\text { Confidence to get health } \\
\text { information }\end{array}$} \\
\hline Full confident & & 1 & \\
\hline Very confident & & $0.64 * * *$ & $(0.55,0.74)$ \\
\hline Some confident & & $0.62^{* * *}$ & $(0.49,0.80)$ \\
\hline \multicolumn{4}{|l|}{ Confidence for self-caring } \\
\hline Full confident & & 1 & \\
\hline Very confident & & $0.83 *$ & $(0.70,1.00)$ \\
\hline Some confident & & $0.57^{* * *}$ & $(0.46,0.70)$ \\
\hline \multicolumn{4}{|l|}{ Heard of CDC } \\
\hline Yes & & 1 & \\
\hline No & & $0.75^{* * *}$ & $(0.62,0.91)$ \\
\hline \multicolumn{4}{|l|}{ Heard of genetic test } \\
\hline Yes & & 1 & \\
\hline No & & $0.86^{* *}$ & $(0.75,0.99)$ \\
\hline \multicolumn{4}{|l|}{ Looking for cancer information } \\
\hline Yes & & 1 & \\
\hline No & & $0.88^{*}$ & $(0.76,1.00)$ \\
\hline \multicolumn{4}{|l|}{ Online access } \\
\hline Yes & & 1 & \\
\hline No & & $0.67^{* * *}$ & $(0.56,0.81)$ \\
\hline \multicolumn{4}{|l|}{ Rating quality healthcare } \\
\hline Excellent & & 1 & \\
\hline Very good & & $0.81 * *$ & $(0.69,0.95)$ \\
\hline Good & & $0.76^{* *}$ & $(0.63,0.93)$ \\
\hline Fair & & $0.67 * *$ & $(0.50,0.89)$ \\
\hline \multicolumn{4}{|l|}{ Trust health info on Internet } \\
\hline A lot & & 1 & \\
\hline Some & & $0.81 * *$ & $(0.67,0.95)$ \\
\hline A little & & $0.76^{* *}$ & $(0.61,0.95)$ \\
\hline Not at all & & $0.67^{* * *}$ & $(0.43,0.76)$ \\
\hline
\end{tabular}

${ }^{*} p<0.05 ; * * p<0.01 ; * * * p<0.001$ 
Table 3. Decomposition of the differences between Hispanics and Whites in percentage reflecting the health statistical confidence gaps.

\begin{tabular}{|c|c|c|}
\hline \multicolumn{3}{|c|}{ Decomposition analysis $^{\text {a. }}$} \\
\hline \multirow[b]{3}{*}{ Whites percentage of health numeracy confidence } & \multicolumn{2}{|c|}{ Hispanic } \\
\hline & Coefficient (SE) & $\%$ \\
\hline & 0.6585 & \\
\hline Hispanics percentage of health numeracy confidence & 0.5604 & \\
\hline Difference & 0.0981 & \\
\hline Age & $-0.014 * * *(0.004)$ & -14.3 \\
\hline Female & $0.0006 * * *(0.00005)$ & 0.6 \\
\hline Education & $0.0244 * * *(0.006)$ & 24.9 \\
\hline Income & -0.0001 & -0.1 \\
\hline Cancer info overload & $-0.0017 * * *(0.0005)$ & -1.7 \\
\hline Confident to get info & $0.0161 * * *(0.003)$ & 16.4 \\
\hline Confident for self-caring & $0.0037 * * *(0.001)$ & 3.8 \\
\hline Looking for cancer info & $0.0042 *(0.005)$ & 4.3 \\
\hline Heard of CDC & $0.0145 * *(0.007)$ & 14.8 \\
\hline Heard of genetic testing & $0.0024 *(0.001)$ & 2.5 \\
\hline Online access & $0.0168 * * *(0.004)$ & 17.1 \\
\hline Rating quality of healthcare & $0.0093 * * *(0.003)$ & 9.5 \\
\hline Trust on Internet & $0.0031 * * *(0.001)$ & 3.2 \\
\hline Observations & 4,119 & \\
\hline All included variables & 0.0794 & 81 \\
\hline
\end{tabular}

${ }^{\text {a. }}$ Negative percentages reflect how a factor contributes to narrowing the gap; positive values imply a widening of the gap between whites and the specific minority group.

$* p<0.05 ; * * p<0.01 ; * * * p<0.001$. 